\title{
PEMANFAATAN HUTAN ADAT OLEH MASYARAKAT SUKU SOUG DI KABUPATEN MANOKWARI SELATAN
}

\author{
(The Use of Customary Forest by Soug Ethnical Community in \\ District of Manokwari Selatan)
}

\author{
DECKY REINGGUP ${ }^{1}$, ANTON SILAS SINERY $^{1 \bowtie}$, CHARLY BRAVO WANGGAI $^{1}$ \\ Jurusan Kehutanan, Fakultas Kehutanan Universitas Papua Manokwari, Papua Barat, 98314. \\ Tlp/Fax: +62986211065. \\ $\bowtie$ Penulis Korespondensi: Email: Sineryanton@yahoo.co.id \\ Diterima: 15 Mar 2020| Disetujui: 24 Apr 2020
}

\begin{abstract}
Abstrak. Tujuan dari penelitian ini adalah untuk mengindentifikasi hutan adat masyarakat Arfak suku Soug dalam pemanfaatan hutan adat di sekitar hutan Tobou. Menilai pemanfaatan hutan, kearifan lokal, pelestarian hutan, transfer ilmu, aksebilitas dan sarana prasarana terhadap eksistensi hutan adat Tobou. Penelitian ini dilakukan dengan metode deskriptif menggunakan data-data kualitatif. Untuk mengumpulkan data digunakan metode interview (wawancara) dan observasi lapang. Dalam pemanfaatan hutan adat di sekitar hutan Tobou terdapat pemanfaatan pembuka lahan kebun, hasil hutan bukan kayu (HHBK), hasil hutan kayu (HHK), sebagai berikut yang adanya nilai-nilai kepercayaan (trust), hubungan timbal balik dan interaksi sosial dalam pemanfaatan lahan dan hutan, masih ada kesatuan masyarakat hukum adat yang kuat, adanya pengaturan-pengaturan secara adat yang kuat dalam masyarakat Arfak, terdapat ikatan sosial yang kuat.
\end{abstract}

Kata kunci: hutan adat, suku Soug, lahan kebun, interaksi sosial, aturan adat

Abstract. The purpose of this study was to identify customary community forest of Soug tribe of Arfak in using customary forest resources surrounding Tobou forest. Through the study, how the forest assessed, local culture, forest preservation, transfer knowledge, accessibility, and infrastructure towards the existence of Tobou customary forest. Descriptive method was used to qualitative data. In order to obtain data, interview and field observation was applied. In terms of customary forest use around Tobou, there were numbers of conserving land types such as garden opening, extracting both, timber and non-timber forest products, important value and trust, co-benefit interaction among social and biophysical co-benefit as a whole ecosystem component and customary role community. It turned out that social bounds among community strata were glaringly seen through customary roles as it has been indicated strong in Arfak ethnic.

Keywords: customary forest, Soug tribe, garden land, social interaction, customary role

\section{PENDAHULUAN}

Undang-Undang No. 41 tahun 1999 telah mendefinisikan bahwa hutan lindung sebagai kawasan hutan yang mempunyai fungsi pokok sebagai perlindungan sistem penyangga kehidupan untuk mengatur tata air, mencegah banjir, mengendalikan erosi, mencegah intrusi air laut dan memelihara kesuburan tanah.

Terkait dengan fungsi lindung, pemerintah telah mengupayakan Undang-Undang 32 Tahun 2009 (tentang Perlindungan dan Pengelolaan Lingkungan Hidup) yang mengamanatkan bahwa perlindungan dan pengelolaan 
lingkungan hidup adalah upaya sistematis dan terpadu yang dilakukan untuk melestarikan fungsi lingkungan hidup dan mencegah terjadinya pencemaran dan/atau kerusakan lingkungan hidup yang meliputi perencanaan, pemanfaatan, pengendalian, pemeliharaan, pengawasan, dan penegakan hukum. Jauh sebelum itu pemerintah telah mengupayakan kebijakan terkait linkungan hidup melalui Kepres 32 tahun 1990 (tentang pengelolaan kawasan lindung) yang mengamanatkan bahwa upaya pengelolaan kawasan lindung mencakup kawasan yang memberikan perlindungan kawasan bawahannya (kawasan hutan lindung, kawasan bergambut, kawasan resapan air), kawasan perlindungan setempat (sempadan pantai, sempadan sungai, kawasan sekitar danau /waduk, kawasan sekitar mata air), kawasan suaka alam dan cagar budaya (kawasan suaka alam, kawasan suaka alam laut dan perairan lainya, kawasan pantan berhutan bakau, taman nasional, taman hutan raya dan taman wisata alam, kawasan cagar budaya dan ilmu pengetahuan) dan kawasan rawan bencana alam.

Masyarakat di sekitar hutan dan masyarakat pada umumnya akan mempunyai sikap yang berbeda dalam menyikapi keberadaan hutan (Marwa et al. 2019). Perbedaan sikap masyarakat dipengaruhi oleh banyak faktor dan kepentingan dari masing-masing individu masyarakat yang berada pada kawasan tersebut. Hal ini terutama dikarenakan pola hidup masyarakat yang berbeda dalam memenuhi kebutuhan hidupnya.

Dalam upaya perlindungan dan pelestarian hutan diperlukan sikap yang positif dari masyarakat, khususnya masyarakat di sekitar hutan. Hal ini dimaksudkan bahwa masyarakat di sekitar hutan tersebut dapat mengetahui dan mengerti manfaat hutan, sehingga keberadaan dan kelestarian hutan dapat terjaga (Tang dkk. 2019). Hutan lindung Maruni I atau Gunung Maruni yang sering disebut oleh Masyarakat sekitar, merupakan salah satu dari hutan lindung yang berada di Kabupaten Manokwari yang ditunjuk berdasarkan Surat Keputusan Mentri Pertanian Republik Indonesia Nomor: $820 / \mathrm{Kpts} / \mathrm{Um} / 11 / 1982$ tanggal 10 Nopember 1982. Kawasan ini telah ditata batas berdasarkan surat perintah tugas Kepala Balai Inventarisasi dan Perpetaan Hutan Manokwari Nomor : 226/VII-SBI.3/1996 dan Surat Perintah Tugas Kepala Cabang Dinas Kehutanan XIV Manokwari Nomor : 800/52 tanggal 29 Januari 1996 dengan hasil tata batas diperoleh panjang batas sepanjang 20,157 kilometer dengan luas 969,84 hektar (Sub BIBHUT Manokwari 1996). Adapun tujuan dari penelitian ini adalah untuk mengidentifikasi cara/bentuk pemanfaatan kawasan hutan lindung Maruni 1 oleh suku Mansim dan menilai manfaat hutan lindung Maruni I secara ekonomi.

\section{METODE PENELITIAN}

Penelitian ini dilaksanakan di Hutan Lindung Maruni 1 Kabupaten Manokwari Provinsi Papua Barat. Waktu pelaksanaan penelitian selama dua minggu yang dimulai dari tanggal 6 Juni - 18 Juni tahun 2016.

\section{Metode dan Teknik Penelitian}

Metode yang digunakan dalam penelitian ini adalah metode deskriptif dengan teknik observasi (survey). Metode deskriptif dengan teknik observasi dilakukan terkait pengambilan data kondisi umum kawasan, dan pemanfaatan lahan. Dilakukan juga wawancara terkait pemanfataan kawasan dengan pemilik hak ulayat.

\section{Prosedur Penelitian}

\section{Kondisi Umum Kawasan}

Pengumpulan data kondisi umum kawasan yang mencakup data primer maupun data sekunder dilakukan melalui observasi lapangan.Pengumpulan data dimaksud 
mencakup data kondisi fisik, biologi dan kondisi sosial ekonomi dan budaya. Secara khusus untuk data kondisi fisik kawasan seperti kondisi iklim, tanah, fisiografi (topografi dan kelerengan), hidrologi dan data tutupan lahan menggunakan data sekunder. Demikian halnya dengan data kondisi biologi dan kondisi sosial masyarakat.

\section{Penentuan Responden}

Pengumpulan data responden dilakukan dengan teknik sensus terhadap seluruh Kepala Keluarga yang berasal dari suku Mansim.

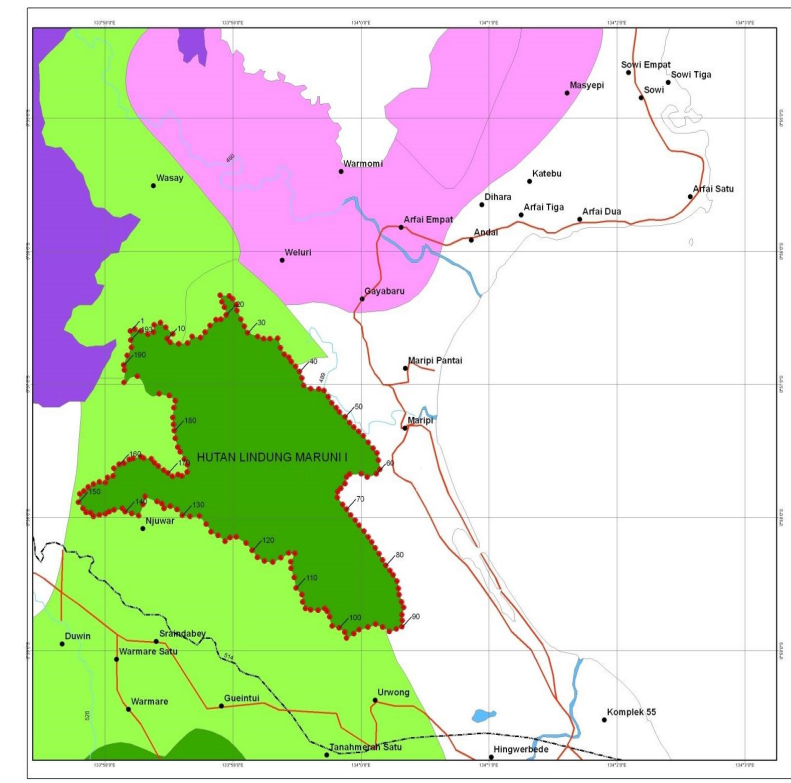

Gambar 1. Peta lokasi penelitian

Jumlah Kepala Keluarga yang diwawancarai secara keseluruhan sebanyak 30 Kepala Keluarga.

\section{Pengolahan Data}

Data yang dikumpulkan dan diolah terdiri atas data primer yaitu data hasil pengamatan dan data sekunder yang diperoleh dari instansi terkait. Data primer yang dikumpulkan terdiri atas:

1. Bentuk/cara pemanfaatan (langsung dan tidak langsung dari hutan dan lahan).
2. Nilai manfaat sumberdaya hutan dan lahan. Nilai manfaat yang dihitung adalah nilai manfaat pertanian, nilai manfaat air, dan nilai manfaat jual kayu. Nilai manfaat hasil pertanian dihitung dengan menggunakan analisis usaha tani. Dimana usaha tani dihitung dengan parameter penjualan atau jumlah produksi dan harga jual serta biaya-biaya yang dikeluarkan.

\section{Nilai Manfaat Pertanian}

Nilai manfaat pertanian dapat dihitung dengn cara perhitungan analisis usaha tani dibawah ini.

Pendapatan $=$ total penerima - total biaya

Penerima $=$ produksi $\times$ harga jual

\section{Nilai Manfaat Air}

Nilai manfaat air dihitung menggunakan pendekatan biaya pengganti (replacement cost). Dimana nilai manfaat air dihitung berdasarkan jumlah pemakaian air untuk rumah tangga. Jumlah kebutuhan air yang diperoleh dalam setiap rumah tangga dalam satuan liter/hari dan dikonversi ke dalam nilai ekonomi.

Untuk menghitung nilai manfaat air digunakan pendekatan harga 1 tanki air minum yang diproduksi di wilayah Maruni dan sekitarnya. Dimana berdasarkan hasil observasi ditemukan bahwa 1 tanki air minum berukuran 5000 liter adalah Rp.250.000,- nilai jual air per tanki dikalikan dengan jumlah air yang dibutuhkan per hari dibagi 5000 liter merupakan nilai manfaat Ekonomi air bagi masyarakat.

\section{Nilai jual kayu}

Nilai mafaat kayu diperoleh berdasarkan harga jual dipasar, untuk menghitung nilai jual kayu diperoleh berdasarkan pendekatan harga jual dipasar dapat dihitung dengan rumus dibawah ini.

Nilai manfaat $\mathrm{kayu}=$ volume $\mathrm{kayu}\left(\mathrm{m}^{3}\right) \times$ harga jual (Rp). 


\section{Eksistensi kawasan Hutan Lindung Maruni I}

Hasil pengamatan langsun dilapangan dan menilai eksistensi kawasan, ancaman-ancman di dalam kawasan tidak ada, yang terjadi ancaman adalah di luar kawasan, tidak ada ancaman di dalam kawasan karena ketinggian tempat oleh sebab itu akses masyarakat atau suku Mansim ke dalam kawasan boleh dikatakan tidak ada. Maka Luas Hutan Lindung Maruni I secara keseluruhan adalah 969,84 hektar dengan panjang 20,157 kilometer yang sudah ditetapkan tersebut dijaga dengan baik eksistensinya.

\section{Analisis Data}

Data hasil penelitian dianalisis secara deskriptif sesuai masing-masing tujuan dan ditampilkan dalam bentuk tabel, gambar atau foto.

\section{HASIL DAN PEMBAHASAN}

\section{Pemanfaatan Kawasan}

Pemanfaatan kawasan merupakan suatu proses terjadinya interaksi individu, populasi atau komunitas khususnya manusia dengan suatu habitat atau lingkungan (Sinery dkk. 2015). Di dalam konteks sumber daya alam hayati pemanfaatan kawasan didasarkan pada obyek sumber daya alam yang dimanfaatkan dan umumnya dikenal sebagai etnobiologi. Etnobiologi sendiri mengandung pengertian adanya pemanfaatan sumber daya alam hayati yang mencakup flora dan fauna (Ungirwalu et al. 2018). Ilmu tersebut mencakup etnobotani dan etnozoologi.

Bentuk-bentuk pemanfaatan sumberdaya hutan oleh suku Mansim terdiri dari beberapa manfaat yaitu:

\section{Sumber Air}

Air merupakan kebutuhan pokok makhluk hidup baik manusia, hewan maupun tumbuhtumbuhan. Manusia yang hidup tidak dekat dengan air, senantiasa mencari tempat tinggal di sekitar air supaya mudah mengambil air untuk memenuhi kebutuhan sehari-hari yang dipergunakan untuk masak, mencuci, mandi dan lain-lain.

Suku Mansim di kampung Maruni memanfaatkan sumber air yang berada di bawa kaki gunung hutan lindung Maruni I, sedangkan di bawa kaki gunung hutan lindung ini terdapat banyak sumber mata air, tetapi belum diketahui berapa jumlahnya, yang dimanfaatkan hanya dua sumber mata air, ke dua sumber air tersebut jaraknya $\pm 50 \mathrm{~m}$ dari kampung Maruni oleh karena itu mudah dijangkau.

Pada waktu musim kemarau kawasan hutan lindung Maruni I mengalirkan aliran-aliran air bawah tanah, dan keluar sebagai mata air pada wilayah dataran. Aliran air yang masuk ke dalam mata air memiliki hubungan dengan kadar pori-pori batuan. Air yang demikian sering disebut dengan istilah air tanah. Air tanah adalah air yang terdapat dalam lapisan tanah atau berbatuan di bawah permukaan tanah.

Air tanah yang digunakan dalam bentuk mata air harus dijaga dengan baik pada sumberdaya. Karena itu kawasan hutan lindung Maruni I harus dijaga dari kerusakan. Apabila tidak dijaga maka air tanah akan berkurang karena pemanfaatan yang terus menerus. Selain itu adanya inutrisi air laut akan mempengaruhi sumur-sumur gali yang dimiliki masyarakat.

\section{Kebun}

Kebun-kebun masyarakat Suku Mansim yang berada di kampung Maruni adalah tidak didalam kawasan hutan lindung Maruni I tapi diluar kawasan, berdasarkan tinjauan langsung ke lapangan kebun yang dibuka yaitu di bawah kaki gunung Maruni. Hasil wawancara dengan suku Mansim yang memanfaatkan lahan-lahan berkebun dimaksud ada punya alasan yaitu (1) karena ketinggian tempat oleh karena itu lahan berkebun yang dimanfaatkan berfokus pada kaki gunung Maruni, selain itu lebih mudah diakses (2) karena dibawah kaki gunung 
Maruni banyak menyimpan unsur hara, dan air oleh karena itu masyarakat atau suku Mansim lebih memilih membuat perkebunan dibawah gunung Maruni, paling banyak kebun-kebun sayur, dan sayur yang dominan yaitu sayur kangkong.

\section{Hasil Hutan}

Hasil hutan yang dimanfaatkan yaitu hasil hutan kayu, berupa penebangan kayu di dalam kawasan HLM I, penebangan kayu yang dilakukan oleh pemilik hak ulayat. Berdasarkan hasil pengamatan langsung di lapangan, sebagai pemilik hak ulayat atau (kepala suku) yang mempunyai kuasa pada wilayah adat tersebut. Pemanfaatan kawasan hutan ini, sebagai usaha kayu log untuk dijadikan kayu gergajian dan dipasarkan berdasarkan pesanan kayu gergajian yang di pesan oleh pembeli-pembeli di kota Manokwari.
Selain itu sebagian dipergunakan untuk pembangunan rumah warga di kampung Maruni. Sesuai dengan kebutuhan sekalipun untuk pembangunan rumah masyarakat tetapi masyarakat sekitar tetap membayar kepada pemilik hak ulayat. Pengamatan langsung di lapangan aktivitas penebangan yang dilakukan yaitu di dalam kawasan. Mereka lakukan penebangan di dalam kawasan, karena mereka belum mengetahui kawasan ini sudah ditetapkan sebagai hutan lindung dan tapal batas kawasanpun belum diketahui oleh mereka. Berdasarkan hasil wawancara dengan pemilik hak ulayat atau (kepala suku) belum ada kejelasan dari pemerintah atau instansi terkait tentang keberadaan hutan ini. Oleh karena itu kepala suku sebagai pemilik hak ulayat mendatangkan operator chainsaw untuk melakukan penebangan di dalam kawasan tersebut dan operator chainsaw ini adalah masyarakat pendatang.

Tabel 1. Nama jenis kayu yang di tebang

\begin{tabular}{lllc}
\hline Nama dagang & Nama ilmiah & Famili & Bentuk pertumbuhan \\
\hline Matoa, Kasai & Pometia pinnata & Sapindaceae & Pohon \\
Merbau, Kayu besi & Intsia bijuga & Fabaceae & Pohon \\
Kayu Susu, Pulai & Alstonia scholaris & Apocynaceae & Pohon \\
Nyatoh, Nyatuh & Palaquium amboinensis & Sapotaceae & Pohon \\
\hline
\end{tabular}

Perlu diketahui bahwa kayu besi yang diproduksi tidak begitu banyak, karena jangkauan untuk mendapatkan kayu besi sudah sangat jauh. Selain itu, dipikirkan juga masalah biaya pembayaran tenaga kerja, harga tenaga kerja ditentukan juga berdasarkan lokasi kerja jangkauannya jauh harganya mahal begitupun sebaliknya.

Selain kayu log, yang dimanfaatkan juga kayu bakar sebagai pengganti bahan bakar minyak tanah, dan kayu bakar yang diambil yaitu dari kebun-kebun mereka sendiri. Mereka lebih memilih kayu bakar karena minyak tanah yang dibutuhkan juga akan mengeluarkan biaya dan tidak hanya biaya pembelian komfor, yang dipikirkan selain itu biaya pembelian sumbu komfor dan agen minyak tanah juga tidak ada. Oleh sebab itu kayu bakar merupak solusi yang baik untuk mereka dalam pemenuhan kebutuhan hidup. 


\section{Manfaat Sumber Mata Air}

Air sebagai sumber kehidupan mempunyai berbagai macam fungsi. Di sisi lain air juga merupakan bagian dari sumberdaya alam. Fungsi air sebagai sumber kehidupan adalah memenuhi kebutuhan air baku untuk rumah tangga, pertanian, industri, pariwisata, pertahanan, pertambangan, ketenagaan dan perhubungan. Sebagai sumberdaya alam air juga harus dilestarikan agar ketersediaan air dipermukaan bumi ini bisa berkesinambungan. Dengan melestarikan hutan berarti melestarikan ketersediaan air sebagai sumberdaya alam. Secara tidak langsung sumberdaya air akan memberikan manfaat ekonomi pada rumah tangga dan pertanian.

Rumah tangga yang mempunyai industri akan membutuhkan air untuk usahanya, petani dalam berusaha tani juga sangat membutuhkan air, baik untuk penyemprotan maupun untuk kebutuhan tanaman itu sendiri. Tanaman yang kekurangan air pertumbuhannya akan terganggu, produktivitas akan berkurang bahkan akan terancam mati. Sebaliknya bila sumber air tersedia tanaman akan tumbuh dengan baik dan produksinya akan tinggi, selain dari manfaat yang tidak langsung, masyarakat di sekitar kawasan hutan juga bisa memanfaatkan hasil hutan langsung, hasil hutan yang didapatkan bisa untuk dikonsumsi sendiri atau untuk dijual sehingga dapat menjadi pendapatan tambahan. Suku Mansim yang berada di kampung Maruni memanfaatkan sumber mata air yang berada di sekitar kawasan HLM I tersebut, yang digunakan untuk masak, mandi, mencuci, lahan pertanian dan kebutuhan lain.

\section{Nilai Manfaat Air}

Berdasarkan hasil wawancara selain sumber mata air yang dikonsumsi, mereka juga mengkonsumsi air sumur, jumlah air yang di butuhkan oleh suku Mansim dalam setiap Kepala Keluarga (KK) untuk masak, mencuci, mandi dan lain-lain dalam satu hari sebanyak 31.170 liter/hari. Untuk mengetahui jumlah kebutuhan air liter/hari disajikan dalam Tabel dibawah ini. Rata-rata air yang dikonsumsi oleh suku Mansim sebanyak 1.039 liter/hari atau $1,04 \mathrm{~m}^{3} /$ hari sebagaimana terlihat pada tabel 2 .

Tabel 2. Jumlah kebutuhan air liter/hari

Kebutuhan air yang digunakan (liter/hari)

\begin{tabular}{cccccl} 
& Masak & Mandi & Mencuci & $\begin{array}{c}\text { Penggunan } \\
\text { lain }\end{array}$ & Total konsumsi \\
\hline Jumlah & 1.570 & 9.200 & 10.000 & 10.400 & 31.170 \\
rata-rata & 52,33 & 306,67 & 333,33 & 346,67 & $1.039 \mathrm{~L} / \mathrm{hari}$ \\
\hline
\end{tabular}

Manfaat air dihitung menggunakan pendekatan biaya pengganti (replacement cost). Dimana nilai manfaat air dihitung berdasarkan jumlah pemakaian air untuk rumah tangga, dan dikonversi ke dalam nilai ekonomi sesuai harga beli air yang berlaku di Distrik Manokwari Selatan. Data jumlah air yang dibayar berdasarkan standar Perusahaan Daerah Air
Minum (PDAM) Manokwari untuk bulan Januari - Mei sebagaimana disajikan pada tabel 3. Berdasarkan data tersebut jumlah konsumsi air untuk Distrik Manokwari Selatan berkisar dari $14.600 \mathrm{~m}^{3}$ /bulan sampai dengan 17.965 $\mathrm{m}^{3}$ /bulan, dengan harga per liter air berkisar dari Rp.4.586 sampai dengan Rp.5.756/ $\mathrm{m}^{3}$ atau

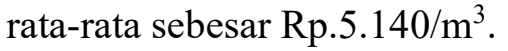


Tabel 3. Penggunaan air $\mathrm{m}^{3}$ /bulan dari (Januari - Mei) di tahun 2016

\begin{tabular}{llc}
\multicolumn{1}{c}{ Bulan } & $\mathrm{m}^{3} /$ bulan & Harga $(\mathrm{Rp}) / \mathrm{m}^{3}$ \\
\hline Januari & 14.600 & 5.008 \\
Februari & 15.949 & 4.586 \\
Maret & 17.965 & 5.027 \\
April & 16.987 & 5.322 \\
Mei & 15.979 & 5.756 \\
Rata-rata & 13.580 & 25.699 \\
\hline
\end{tabular}

Sumber : PDAM Manokwari, 2016.

Bila harga penggunaan air selama lima bulan di Distrik Manokwari Selatan digunakan untuk menghitung nilai air yang dikonsumsi oleh suku Mansim maka diperoleh angka sebagaimana disajikan pada tabel 4.

Tabel 4. Jumlah konsumsi air dan nilai manfaat ekonomi air

\begin{tabular}{lccc}
\hline & $\begin{array}{c}\text { Jumlah konsumsi } \\
\text { air }\left(\mathrm{m}^{3}\right)\end{array}$ & $\begin{array}{c}\text { Harga per meter } \\
\text { kubik }\left(\mathrm{Rp} / \mathrm{m}^{3}\right)\end{array}$ & $\begin{array}{c}\text { Nilai manfaat ekonomi air } \\
\left(\mathrm{Rp} / \mathrm{m}^{3}\right)\end{array}$ \\
\hline Konsumsi air/hari & 31,170 & 5.140 & 160.214 \\
Konsumsi/bulan & 935,10 & 5.140 & 4.806 .414 \\
Konsumsi/tahun & $11.221,20$ & 5.140 & 57.676 .968
\end{tabular}

Nilai manfaat air bagi suku Mansim di sekitar hutan lindung Maruni I per hari sebesar Rp. $160.214 / \mathrm{m}^{3}$ dan nilai konsumsi per tahun sebesar Rp.57.676.968. $/ \mathrm{m}^{3}$. Bila nilai manfaat ini dihitung berdasarkan jumlah $\mathrm{KK}$ maka total konsumsi per tahun adalah sebesar Rp.1.922.566/ $\mathrm{m}^{3} / \mathrm{KK}$. Sebagai perbandingan dalam studi ini juga digunakan pendekatan biaya penggantian menggunakan tarif tanki yang berlaku di Distrik Manokwari Selatan. Dimana harga satu tangki air yang berkapasitas 5000 liter adalah Rp.250.000,-. Berdasarkan data yang diperoleh total konsumsi air untuk suku Mansim dalam sehari sebesar 31.170 liter, jumlah ini setara dengan 6 tanki air. Dengan demikian nilai manfaat air dalam sehari adalah sebesar Rp.1.500.000,- seperti pada tabel 5 .

Tabel 5. Nilai manfaat ekonomi air di distrik Manokwari Selatan berdasarkan tarif tanki air

\begin{tabular}{lcc}
\hline Jumlah konsumsi air & $\begin{array}{c}\text { Harga per tangki } \\
(\mathrm{Rp})\end{array}$ & $\begin{array}{c}\text { Nilai manfaat air } \\
(\mathrm{Rp} / \mathrm{liter})\end{array}$ \\
\hline 6 tanki (per hari) & $250.000,-$ & $1.500,000.00$ \\
180 tanki (per bulan) & $250.000,-$ & $46.755,000.00$ \\
2160 tanki (per tahun) & $250.000,-$ & $561.060,000.00$
\end{tabular}


Jadi secara keseluruhan nilai manfaat ekonomi air bagi suku Mansim di kawasan hutan lindung Maruni I dalam satu tahun mencapai Rp.561.060.000,- dengan demikian air di wilayah ini bukan lagi sebagai barang bebas tetapi telah berubah menjadi barang ekonomi.

\section{Manfaat Pertanian}

Manfaat pertanian tentunya kita akan melihat secara lebih besar pada masyarakat pedesaan, karena pedesaan merupakan tempat pelaksana pertanian utama dalam memenuhi kebutuhan pangan hidup manusia baik itu masyarakat perkotaan maupun masyarakat pedesaan sendiri.

Pertanian yang dimanfaatkan oleh suku Mansim di kampung
Maruni adalah untuk memenuhi kebutuhan dasar rumah tangga mereka dan mensejahterakan ekonomi keluarga. Pengamatan langsung di lapangan di sekitar kawasan hutan lindung tersebut menunjukan bahwa hampir sebagian besar suku Mansim memanfaatkan lahan pertanian dilihat dari mata pencaharian sebagian besar mata pencahariannya petani oleh karena itu, pertanian yang dimanfaatkan sangat mempunyai peran penting bagi mereka.

\section{Nilai Manfaat Pertanian}

Nilai manfaat pertanian yang diperoleh juga sangat menguntungkan mereka terutama untuk memenuhi kebutuhan ekonomi keluarga, hasil usaha pertanian yang mereka ambil sebagian dikonsumsi dan sebagian juga dijual dipasar.

Tabel 6. Usaha pertanian

\begin{tabular}{llcccc}
\hline $\begin{array}{l}\text { Hasil } \\
\text { pertanian }\end{array}$ & $\begin{array}{c}\text { Jumlah produksi } \\
\text { yang dijual/bulan }\end{array}$ & $\begin{array}{c}\text { Harga } \\
\text { satuan (Rp) }\end{array}$ & $\begin{array}{c}\text { Penerima } \\
(\mathrm{Rp})\end{array}$ & $\begin{array}{c}\text { Biaya } \\
(\mathrm{Rp})\end{array}$ & $\begin{array}{c}\text { Pendapatan/bulan } \\
(\mathrm{Rp})\end{array}$ \\
\hline Jagung & 20 Tumpuk & 10.000 & 200.000 & 20.000 & 180.000 \\
Keladi & 10 Tumpuk & 20.000 & 200.000 & 15.000 & 185.000 \\
Petatas & 5 Tumpuk & 10.000 & 50.000 & 20.000 & 30.000 \\
Singkong & 10 Tumpuk & 10.000 & 100.000 & 20.000 & 80.000 \\
Pisang & 10 Sisir & 15.000 & 150.000 & 15.000 & 135.000 \\
$\begin{array}{l}\text { Sayur- } \\
\text { sayuran }\end{array}$ & 20 Ikat & 5000 & 100.000 & 15.000 & 85.000 \\
\hline Jumlah & $75 \mathrm{~kg}$ & 70.000 & 800.000 & 105.000 & 695.000 \\
\hline
\end{tabular}

Niai manfaat pertanian dapat dihitung dengan menggunakan analisis usaha tani yaitu pendapatan sama dengan total penerima dikurangi dengan total biaya. Pendapatan per bulan yang mereka dapat adalah sebesar Rp.695.000,- Sedangkan pendapatan per tahun dari aktifitas pertanian di sekitar hutan lindung adalah sebesar Rp.8.340.000.

\section{Manfaat Jual Kayu}

Di hutan tumbuh beraneka spesies pohon yang menghasilkan kayu dengan berbagai ukuran dan kualitas yang dapat digunakan untuk bahan bangunan dan mempunyai nilai ekonomi yang tinggi. Tingkat biodiversitas hutan sangat tinggi dan memberikan banyak manfaat bagi manusia yang tinggal di sekeliling hutan. Selain kayu bangunan, hutan juga menghasilkan beraneka hasil yang dapat dimanfaatkan secara langsung sebagai obatobatan, sayuran dan keperluan rumah tangga lainnya (Cabuy et al. 2012).

\section{Nilai Manfaat Kayu}

Kayu mempunyai nilai ekonomi, oleh karena itu suku Mansim yang berada di kampung 
Maruni ini memanfaatkan kayu-kayu yang diporoduksi dari sekitar kawasan hutan lindung Maruni I, hal tersebut dilakukan karena untuk memenuhi kebutuhan ekonomi keluarga, penebangan yang dilakukan secara ilegal oleh pemilik hak ulayat yang berada di daerah tersebut kayu-kayu hasil produksi tersebut dipasarkan pada stand-stand kayu yang ada di kota Manokwari (Paririe dkk. 2019).

Nilai manfaat kayu diperoleh berdasakan harga jual dipasar, hasil produksi kayu yang dijual yaitu kayu balok $5 \mathrm{~cm} \times 10 \mathrm{~cm} \times 400 \mathrm{~cm}$ degan harga Rp.1.500.000,- per $\mathrm{m}^{3}$, sedangkan kayu balok $10 \mathrm{~cm} \times 10 \mathrm{~cm} \times 400 \mathrm{~cm}$ dengan harga jual sebesar Rp.2.500.000,- dan papan 2,5 $\mathrm{cm} \times 25 \mathrm{~cm} \times 400 \mathrm{~cm}$ dengan harga Rp.1.500.000,- per $\mathrm{m}^{3}$. Misalkan hasil produksi kayu balok $5 \mathrm{~cm} \times 10 \mathrm{~cm} \times 400 \mathrm{~cm}$ yang dihasilkan sebanyak $3 \mathrm{~m}^{3}$ dan dikalikan dengan harga jual Rp.1.500.000,- maka akan mendapatkan Rp.4.500.000,- dan kayu balok 10 $\mathrm{cm} \times 10 \mathrm{~cm} \times 400 \mathrm{~cm}$ misalkan yang peroleh sebanyak $2 \mathrm{~m}^{3}$ dan dikalikan dengan harga jual Rp.2.500.000,- maka akan mendapatkan Rp.5000.000,- begitupun dengan papan $2,5 \mathrm{~cm}$ $\times 25 \mathrm{~cm} \times 400 \mathrm{~cm}$ papan yang diperoleh juga 2 $\mathrm{m}^{3}$ misalkan, dan dikalikan dengan harga jual Rp.1.500.000,- maka hasilnya adalah Rp.4.500.000,-.

Selain dipasarkan di stan-stan kayu, mereka juga memasarkan di kampung Maruni sesuai kebutuhan masyarakat yang memesan untuk pembangunan perumahan mereka harganyapun berbeda dengan harga jual di stan-stan kayu, ada yang harganya $\mathrm{Rp} .1000 .000$,- per $\mathrm{m}^{3}$ untuk kayu balok $5 \mathrm{~cm} \times 10 \mathrm{~cm} \times 400 \mathrm{~cm}$ dan papan $2,5 \mathrm{~cm} \times 25 \mathrm{~cm} \times 400 \mathrm{~cm}$ sedangkan kayu balok $10 \mathrm{~cm} \times 10 \mathrm{~cm} \times 400 \mathrm{~cm}$ harganya Rp.2.000.000,- per $\mathrm{m}^{3}$ sedikit berbeda dengan papan dan balok $5 \mathrm{~cm} \times 10 \mathrm{~cm} \times 400 \mathrm{~cm}$.

\section{Nilai Manfaat Total Kawasan Hutan}

Secara total nilai keberadaan hutan lindung Maruni I bagi suku Mansim memiliki nilai manfaat yang cukup besar seperti pada tabel 7 .

Tabel 7. Nilai manfaat total kawasan hutan

\begin{tabular}{lll}
\hline Bentuk manfaat & Nilai Manfaat/bulan & Manfaat/tahun \\
\hline Sumber Air & Rp.4.806.414,- & Rp.57.676.968,- \\
Pertanian & Rp.695.000,- & Rp.8.340.000,- \\
Penjualan Kayu & Rp.5.000.000,- & Rp.60.000.000,- \\
Total & Rp.10.501.414,- & Rp.126.016.968,- \\
\hline
\end{tabular}

Pada tabel diatas jumlah total dari bentuk pemanfaatan kawasan hutan lindung Maruni I yang dimanfaatkan oleh suku Mansim, untuk nilai manfaat sumber air per bulannya yang diperoleh sebesar Rp. 4.806.414,- sedangkan untuk per tahunnya sebesar Rp.57.676.968,dan untuk nilai manfaat pertanian per bulan yang dihasilkan yaitu sebesar Rp.695.000,sedangkan untuk per tahun yang mereka dapat adalah Rp.8.340.000,- begitu juga dengan nilai manfaat penjualan kayu per bulan sebesar Rp.5000.000,- dan per tahun adalah Rp.60.000.000.

\section{KESIMPULAN}

Hutan lindung Maruni I memiliki bentuk manfaat untuk aktifitas pertanian, penjualan, kayu dan sumber air. Manfaat pertanian, 
manfaat jual kayu, manfaat sumber mata air mempunyai nilai ekonomi bagi suku Mansim yang memanfaatka areal tersebut terutama dalam memenuhi kebutuhan hidup sehari-hari. Nilai manfaat pertanian dan kayu sangat menjawab kebutuhan ekonomi suku Mansim yang memanfaatkan areal kawasan hutan lindung Maruni I dilihat dari jumlah produksi pertanian dan harga jual kayu yang dihasilkan. Jumlah total nilai manfaat hutan lindung Maruni I oleh suku Mansim per bulan sebesar Rp.10.501.414,- atau setara dengan Rp.126.016.968,-per tahun. Sehingga dengan demikian, nilai manfaat hutan lindung Maruni I menunjukkan bahwa kawasan tersebut 'penting' bagi suku Mansim dan generasi berikutnya.

\section{DAFTAR PUSTAKA}

Cabuy RL, Marwa J, Manusawai J, Rahawarin YY. 2012. Non-woody plant species of Papuan Island forests, a sustainable source of food for the local communities. Indian Journal of Traditional Knowledge. 11(4): 586-592.

Marwa J, Sardjono MA, Ruchaemi A, Devung S, Cabuy RL. 2019. Benefit sharing schema from the forest: Identifying potential distributions to customary communities in Teluk Bintuni district, Indonesia. Acta Universitatis Agriculturae et Silviculturae Mendelianae Brunensis. 67(4): 963-972. $\underline{\text { https://doi.org/10.11118/actaun20196704096 }}$ $\underline{3}$

Paririe FD, Marwa J, Panambe N. 2019. Tingkat pendapatan pengusaha kayu gergajian berdasarkan margin keuntungan dan alur pemasaran kayu lokal di distrik Manokwari Utara. Jurnal Kehutanan Papuasia. 5(2): 196-206. DOI: https://doi.org/10.46703/jurnalpapuasia .Vol5.Iss2.161.

Sinery A, Anggrianto R, Rahawarin YY, Peday HFZ. 2015. Potensi dan strategi pengelolaan hutan Wosi Rendani. Penerbit Depublish, Yogyakarta.

Sub BIPHUT Manokwari. 1996. Berita acara tata batas. Manokwari.

Tang M, Malik A, Hapid A. 2019. Pemanfaatan hasil hutan bukan kayu (HHBK) bambu oleh masyarakat terasing (suku Lauje) di desa Anggasan kecamatan Dondo kabupaten Tolitolo. Jurnal Warta Rimba. 7(2): 19-26.

Undang-Undang Nomor 41 Tahun 1999 Tentang Kehutanan, Jo. Undang - Undang No. 19 Tahun 2004 Tentang Perubahan Kedua Atas Undang-Undang 41 Tahun 1999 Tentang Kehutanan.

Ungirwalu A, Awang SA, Tokede MJ. 2018. Etnobotani buah hitam: Konstruksi etnoekologi etnis Wandamen Papua. Penerbit Deepublish, Jl. Kaliurang, Yogyakarta. 